\title{
A Lei do Desejo e o Desejo Produtivo: Transgressão da Ordem ou Afirmação da Diferença?
}

CARLOS AUGUSTO PEIXOTO JUNIOR ${ }^{l}$

$\mathrm{O}$ artigo pretende confrontar as concepções de desejo nas teorias de Jacques Lacan e Gilles Deleuze, respectivamente, apresentando algumas diferenças entre um modelo hegeliano, pautado na lei, na falta e na negatividade, e outro, nietzscheano, baseado na afirmação e na produção. Assim, torna-se possível pensar em duas formas de subjetivação também diversas, uma centrada na visão edipiana, e outra proveniente da crítica desse modelo matricial. Com isso, pretende-se ainda contrapor à idéia de uma transgressão negativa, fundada na renegação da lei e da ordem, uma concepção de transgressão criadora ou positiva, baseada na afirmação da diferença.

Palavras chave: Desejo; lei; transgressão; Lacan; Deleuze. 


\section{Introdução}

Este trabalho tem como objetivo principal confrontar as concepções de desejo nos pensamentos de Jacques Lacan e Gilles Deleuze, respectivamente, procurando mostrar, em linhas gerais, as diferenças entre um modelo pautado na lei, na falta e na negatividade, e outro baseado na afirmação da produção e na positividade do excesso. Com isso pretendemos também esboçar alguns traços dominantes de duas formas de subjetivação diversas: a primeira centrada prioritariamente numa visão edipiana, e a segunda, proveniente da crítica desse modelo matricial. Para delimitar melhor o problema, gostaríamos de esclarecer desde já que tomaremos como referência maior do pensamento lacaniano o período que privilegia o registro do simbólico como campo prioritário de articulação do desejo, assim como as críticas deleuzianas que se dirigem mais diretamente a esse tipo de leitura do conceito. No caso de Lacan, partimos do pressuposto de que é o pensamento de Hegel que serve de inspiração para a sua compreensão do desejo. Do mesmo modo, vemos em Nietzsche a referência central para as críticas ao modelo lacaniano e para a concepção das máquinas desejantes formulada por Deleuze. Traçadas as linhas gerais de cada uma dessas perspectivas, acreditamos que seja possível contrapor à idéia de uma transgressão negativa, fundada na renegação da lei e da ordem, uma concepção de desejo baseada na afirmação da diferença, a qual se caracteriza pelo que chamaremos de transgressão criadora ou positiva.

\section{Lacan e a Negatividade do Desejo}

Sabe-se que a obra de Jacques Lacan não apenas se apropria do discurso hegeliano sobre o desejo, mas também delimita radicalmente o seu significado, através da transposição de certos temas da Fenomenologia do espírito (Hegel, 1941) para uma moldura psicanalítica de cunho estruturalista. De acordo com Lacan, o desejo não pode mais ser equacionado através da estrutura fundamental da racionalidade humana, como queria Hegel. Ele também não pode mais ser pensado como aquilo que revela ou expressa a estrutura reflexiva da consciência, mas, ao contrário, deve ser entendido como um momento preciso de sua opacidade. Neste sentido, ele é justamente o que a consciência em sua reflexividade procura dissimular, uma espécie de anseio do qual ela sofre, e que só se revela nas suas rupturas. O desejo, portanto, não se expressa senão pelas descontinuidades da consciência e deve ser entendido como a sua própria 
incoerência interna.

Pensado deste ponto de vista, o desejo indica a impossibilidade de um sujeito coerente, entendido como instância consciente autodeterminada. A significação dessa instância estaria sempre previamente determinada por um significante inconsciente, o qual escapa às suas pretensões de clareza absoluta. Trata-se aqui do famoso sujeito dividido lacaniano, separado de sua unidade libidinal originária com o corpo materno, num processo que supõe o recalque originário como o principal operador da individuação. Assim o desejo é a expressão de um anseio de retorno à origem que, acaso recuperada, exigiria a dissolução do próprio sujeito. Segundo Lacan, é justamente essa impossibilidade de recuperação das origens que faz do sujeito um limite para a satisfação. $\mathrm{Na}$ medida em que emerge como uma contradição interna, fundando-se numa defesa necessária contra a união libidinal primeira com a mãe, o sujeito é basicamente o produto de uma proibição. Seu desejo é uma espécie de resíduo daquela união precoce, a memória afetiva daquele prazer anterior à individuação. Nestes termos, o desejo é ao mesmo tempo um esforço para dissolver o sujeito que barra o caminho para o prazer, e a evidência atual da impossível recuperação desse prazer.

Essa contradição interna do sujeito não poderia ser resolvida pela produção de uma síntese dialética, mas também não pode ser compreendida como um paradoxo insolúvel. Na verdade, a barreira ou proibição que separa o sujeito do inconsciente é uma operação negativa que fracassa em mediar o que ela separa. Isso significa que a negatividade do recalque não pode sequer ser compreendida pela Aufhebung (suspensão) hegeliana. Isto é o que se pode deduzir do famoso debate entre Lacan e Jean Hyppolite, em torno do conceito de Verneinung (denegação) (Lacan, 1966, p. 369). Segundo Lacan, a falta característica da estrutura inconsciente nunca poderia ser tematizada de maneira apropriada, e a denegação que a incorpora não funciona em termos de uma relação positiva, intrinsecamente relacionada com o que está sendo denegado, tal como Hyppolite parece sugerir. Ela na verdade opera através dos mecanismos de deslocamento e condensação, o que implica que aquilo que se coloca através do ato de denegação não tenha nenhuma relação necessária com o que está sendo negado, mas esteja apenas associativamente relacionado com ele.

Argumentando que a significação do negativo está na dependência do deslocamento do significado, Lacan afirma que a linguagem que pretensamente 
representa essa negatividade só o faz através de seu encobrimento. Nestas condições, de acordo com Judith Butler, "a positividade da linguagem é uma parte do estratagema da própria denegação" (Butler, 1987, p. 188), e a representação é em geral compreendida como fundada numa repressão necessária do inconsciente. A linguagem não é mais entendida como algo que está internamente relacionado ao negativo, mas como aquilo em que se baseia a divisão do sujeito do inconsciente e que continuamente provoca essa divisão através dos mecanismos de metáfora e metonímia.

Lacan critica explicitamente Hegel por restringir sua análise do desejo à autoconsciência. $\mathrm{O}$ resultado dessa operação é que o inconsciente se vê desconsiderado como significante da atividade consciente, e a consciência passa a ser privilegiada como falso lugar do significante. Na verdade, a divisão entre consciente e inconsciente traria conseqüências para a obscuridade fundamental do desejo. A opacidade do significante que determina o "Eu" é o próprio inconsciente enquanto cadeia de significantes, o qual interfere repetidamente na auto-apresentação coesa e coerente do sujeito consciente. Nesse sentido, o inconsciente não é concebido topograficamente, mas em termos das várias negatividades - faltas, furos, fissuras - que marcam o discurso do Eu. Nas palavras de Lacan, "o inconsciente freudiano (...) se situa neste ponto em que, entre a causa e o que ela afeta, há sempre claudicação" (Lacan, 1979, p. 27). $\mathrm{O}$ que significa antes de tudo que o inconsciente aparece primeiramente como um fenômeno em forma de descontinuidade e vacilação (Lacan, 1966, p. 299).

O inconsciente é, portanto, o não realizado que só se torna presente no discurso através de inúmeras hesitações, tais como deslocamentos, condensações, denegações e outras significações metonímicas. Em termos lacanianos, "a lacuna do inconsciente pode ser considerada pré-ontológica" (Lacan, 1966, p. 329), no sentido em que ela precede a ontologia do sujeito e constitui um universal inquestionável. Isso porque o inconsciente delimita o contexto no qual qualquer discurso sobre a ontologia poderia ter lugar. A função do inconsciente em qualquer sujeito indica essa dimensão universal, embora em nenhum caso a brecha entre significante e significado venha a ser recoberta, como ocorreria na hipótese da síntese hegeliana. Deste ponto de vista, "a identidade só se realiza como disjuntiva quanto ao sujeito" (Lacan, 1966, p. 230). Considerando-se que tal disjunção é universalmente constitutiva da experiência e da cultura humanas, o inconsciente lacaniano é pura negatividade que só chega a existir através de uma representação substitutiva consciente. 
No entanto, essa expressão é arbitrária e a diferença entre significante e significado continua a ser absolutamente irremediável.

Essas são algumas das operações que tornam possível descrever o inconsciente como discurso do Outro, da cadeia de significantes que constitui o elo de associações metonímicas na linguagem. Conseqüentemente, estar na linguagem é apresentar-se como um Outro inerradicável, como a alteridade da própria significação que constantemente escapa às intenções subjetivas. Assim, não é o sujeito que é alienado de si mesmo, caso no qual um princípio de identidade ainda se sustentaria de maneira velada. Na verdade, o sujeito é alienado no próprio significante que inexoravelmente o divide. Essa divisão é analisada por Lacan a partir do recalque dos desejos edipianos e concebida como uma proibição fundadora, ou fundamental, que sobrevive no desejo como Lei do significante, a qual condiciona a individuação do sujeito. Esse recalque primário também constitui o desejo como falta, ou seja, como uma resposta à separação originária, que é menos a separação do nascimento do que o resultado da proibição da união incestuosa. É por isso que o desejo é tido como um querer-ser ou uma falta-a-ser (Lacan, 1979, p. 33), perpetuamente frustrada por causa de sua sujeição à Lei do Significante. Esse complexo raciocínio leva a pensar que se o desejo se faz representar na linguagem, ele só o faz sob a forma de uma presença oblíqua: sempre associado à sua proibição, ele assume a forma de uma ambivalência necessária.

Elaborando a distinção freudiana entre o alvo e o objeto da pulsão (Freud, 1994), Lacan entende o projeto implícito ao desejo como recuperação do passado através de um futuro que necessariamente o interdita. $\mathrm{O}$ desejo seria então o pathos do ser cultural ou do sujeito pós-edipiano: ele "é uma falta engendrada há tempos atrás que serve para responder à falta criada pelo tempo que se segue" (Lacan, 1979, p. 221). A proibição que o constitui é precisamente o que interdita sua satisfação final; em conseqüência, o desejo estaria sempre correndo contra um limite que, paradoxalmente, o sustenta enquanto tal. O desejo então seria uma atividade incansável dos seres humanos que mantém sua inquietação com relação a um limite necessário.

Outro aspecto interessante é que Lacan aceita a distinção entre os desejos humano e animal, dando a este último o nome de necessidade. Assim como para Alexandre Kojève (1968) - grande comentador de Hegel, cujos cursos ele frequientou nos anos 30 -, o desejo em Lacan também se distingue através de suas manifestações no discurso, o que faz da verbalização sua 
precondição necessária. No entanto, diferentemente de Kojève, Lacan ressalta que a cadeia metonímica de associações através das quais o desejo humano fala é o lugar de sua opacidade intratável. Seguindo Hyppolite (1971), ele concorda que o desejo é sempre desejo do outro, mas também lembra que este nunca pode ser satisfeito na medida em que o Outro, o inconsciente, permanece, em última instância, opaco. Em função disso, afirma Butler, o desejo "existe como uma discrepância entre a necessidade (impulso biológico) e a demanda (que é sempre demanda de amor, de reconhecimento completo através da recuperação da união pré-edipiana)" (Butler, 1987, p. 192). "Assim, ele não é nem o apetite de satisfação nem a demanda de amor, mas a diferença que resulta da subtração do primeiro à segunda, o próprio fenômeno de sua divisão" (Lacan, 1966, p. 691). O desejo, portanto, aparece como uma fenda, uma discrepância, um significante ausente e, neste sentido, só aparece como aquilo que não pode verdadeiramente aparecer. Isto porque o desejo nunca se materializa ou se concretiza na linguagem, mas é apenas indicado através de seus interstícios, ou seja, através daquilo que a linguagem não pode representar em termos absolutos.

Nota-se que o desejo, neste tipo de leitura, está sempre vinculado a um projeto de recuperação impossível, no qual o que deve ser recuperado é tanto o campo libidinal reprimido, constitutivo do inconsciente, quanto o "objeto perdido", a mãe pré-edipiana. Um projeto como esse é impossível precisamente porque o sujeito pretende ser idêntico ao significante, e mesmo uma identificação desse tipo é interditada pela própria linguagem que o divide desde sempre. $\mathrm{Na}$ verdade, o sujeito é aquilo que substitui o objeto perdido e pode ser compreendido como a incorporação dessa perda. De acordo com Lacan, ele é "a introdução de uma perda na realidade (...) quando o sujeito toma o lugar da ausência, introduz-se na palavra uma perda, e esta é a definição do sujeito" (Lacan, 1976, p. 205-206). E é por isso que o discurso de um tal sujeito só pode ser pronunciado enigmaticamente através das suas ausências. Esse discurso indica ao mesmo tempo a "perda" que ele representa e anuncia a superação da perda pelo desejo. Ele é necessariamente o discurso de um desejo deslocado, que estabelece analogias constantes entre o objeto perdido e o objeto presente, construindo falsas certezas na base de similaridades parciais.

Conseqüentemente, o sujeito que fala é um sujeito "evanescente", que está sempre desaparecendo no inconsciente que ele representa. Constituído a partir da representação dessa perda desejada, ele vacila frequientemente entre sua própria particularidade e o Outro perdido, o qual, com efeito, também é 
representado por ela. Nota-se, portanto, que Lacan entende o desejo como um princípio de deslocamento lingüístico presente na função metonímica de toda significação. Nas palavras do autor,

\begin{abstract}
"a relação entre o sujeito barrado e o objeto (a) é a estrutura que sempre se encontra no fantasma que sustenta o desejo, na medida em que o desejo é tão-somente aqui o que chamei de metonímia de toda significação" (Lacan, 1976, p. 206).
\end{abstract}

O efeito da articulação do desejo é então o perpétuo deslocamento do significado. Na medida em que a demanda de amor presente no desejo é demanda de prova ou evidência de amor, o desejo está articulado não com o objeto que o satisfaria, mas com um objeto originalmente perdido, proibido pela Lei do Pai e em consonância com a Lei do Significante. Sendo assim, poderíamos dizer que a afirmação lacaniana de que "o desejo do homem é o desejo do Outro" é a sua versão para o Absoluto de Hegel, pois o desejo do Outro é tanto a origem quanto o alvo final da demanda de amor. Esse Absoluto, o "ser" faltoso, é também chamado de gozo: a completude de um prazer sempre frustrado pela dor da individuação edipianamente condicionada.

Na medida em que o desejo busca implicitamente a recuperação impossível do gozo, através de um Outro que não é o seu objeto originário, o processo desejante transforma-se numa série de desconhecimentos necessários que nunca são completamente resolvidos. Como é o recalque que funda o desejo, a decepção parece ser sua única contrapartida necessária. Com isso, a apreensão do desejo como desejo do Outro só é possível através da escuta do que não é dito, do que é denegado, omitido ou deslocado. Citando Lacan, "o sujeito encontra uma falta na própria intimação que o Outro lhe faz através de seu discurso" (Lacan, 1979, p. 223). A cadeia de significações, associações e substituições metonímicas que "re-presentam" o desejo do Outro é simultaneamente um deslocamento desse desejo, o que faz com que o esforço pelo reconhecimento seja sempre desviado de seu curso. Admitindo que o sujeito hegeliano é autotransparente, Lacan confia à psicanálise a introdução da noção de opacidade na doutrina hegeliana do desejo (Lacan, 1966, p. 813).

No entanto, as formulações hegelianas não lhe parecem completamente equivocadas, pois, enquanto demanda, o desejo é também um projeto de conhecimento. Ainda que não possa ser propriamente assimilado à demanda, existindo como o diferencial entre ela e a necessidade, o desejo em sua versão 
lacaniana mantém algo da busca transcendente pela presença que caracteriza os pensadores hegelianos. Segundo Lacan,

"a demanda nela própria vincula-se a alguma outra coisa para além das satisfações que ela solicita. Ela é demanda da presença de uma ausência - que se manifesta na relação primordial com a mãe" (Lacan, 1966, p. 634).

O caráter transcendente da demanda manifesta seu completo desprezo por demonstrações particulares de afeto ou, dito de outro modo, faz com que ela apreenda toda e qualquer demonstração particular a partir da prova incondicional de amor que ela deve representar. Na verdade, a demanda pode resultar na completa renúncia às necessidades, pois as satisfações das mesmas aparecem como demonstrações de atenção particularmente falsas, fortuitas, insignificantes e sem qualquer utilidade para aquela demanda de amor incondicional. Nesse contexto, o desejo emerge como uma espécie de mediador sacrificial, aquele pelo qual a realização da mediação é impossível. Ele desempenha o papel de paradoxo nas relações entre necessidade e demanda, e não pode nunca efetuar uma unidade harmônica entre necessidades particulares e demandas universais, mas apenas elaborar a contradição, perseguindo mundanamente, sem qualquer esperança, o impossível.

Se o desejo emerge como uma atividade necessariamente paradoxal, também podemos encarar sua versão lacaniana como uma transposição para a psicanálise da noção de desejo em Hyppolite. Indicando como a necessidade continua a residir no exercício do desejo, Lacan revelaria a ingenuidade fenomenológica da estrita distinção kojèviana entre desejo e necessidade. Além disso, no entanto, a articulação do desejo no discurso desvendaria o simbolismo essencialmente romântico que governa as teorias da linguagem e da expressão em Hegel, Kojève e Hyppolite. Como mostramos anteriormente, estar na linguagem, para a psicanálise lacaniana, significa estar infinitamente deslocado com relação a uma significação original. E, posto que o desejo se constitui dentro desse campo lingüístico, ele está constantemente em busca daquilo que não quer realmente, como se estivesse sempre querendo o que não pode finalmente obter. O desejo significa o domínio de uma contradição irreparável.

Entretanto, Lacan se mantém aprisionado ao discurso de Hegel, na medida em que para ele a demanda retém o ideal hegeliano e o desejo permanece portador de más notícias ontológicas. Não há dúvida de que ele encontrou na dialética do desejo uma visão preferível ao discurso fisiológico sobre o instinto 
que predominou em determinados círculos psicanalíticos. Absolutamente cônscio das falsas promessas de progressão e unidade oferecidas pelas explanações fenomenológicas de Hegel (1941), Lacan permanece convencido de que a dialética contém traços de valor universal, os quais seriam indiretamente confirmados pelos achados do estruturalismo e da psicanálise. Ele argumenta que a noção hegeliana de desejo possibilita uma contraposição à tradução inglesa do Trieb como instinto, na medida em que ela é portadora da ambigüidade originalmente pretendida por Freud para a pulsão (Lacan, 1966, p. 851-854). A demanda de amor sob a qual trabalha o desejo, ou seja, a sombra inexorável sob a qual ele existe, é ela própria irredutível à necessidade fisiológica. Deste ponto de vista, o desejo especificamente humano de reconhecimento incondicional não poderia de modo algum ser reduzido ao materialismo bruto da vida afetiva.

Lacan, portanto, vê em Hegel uma espécie de corretivo crucial para o reducionismo materialista de uma teoria psicanalítica baseada na fisiologia. No entanto, porque o desejo é o diferencial entre a demanda e a necessidade, ele existe, por assim dizer, a meio caminho entre o silêncio e a fala/discurso. Entre o silêncio intratável da necessidade e o logocêntrico clamor da demanda, o desejo é o momento no qual os limites da linguagem são incessantemente problematizados. A firme convicção lacaniana de que nenhuma forma lógica ou lingüística pudesse reconciliar essa diferença marca sua ruptura com o otimismo ontológico de Hegel. Numa passagem de um de seus escritos mais famosos, "Subversão do sujeito e dialética do desejo", ele afirma que, "longe de ceder a uma redução logicizante quando se trata da questão do desejo, encontramos na sua irredutibilidade à demanda a própria fonte do que sempre o impede de ser remetido à necessidade. Colocando de maneira elíptica: é precisamente porque o desejo é articulado que ele não é articulável" (Lacan, 1966, p. 804). Assim, Lacan defende Hegel, quando se opõe à naturalização da teoria psicanalítica e o critica quando argumenta contra a postulação de um sujeito autônomo.

De qualquer forma, parece que o desejo em Lacan continua em busca do Absoluto. Este, no seu entendimento, estaria fundado na constituição da crença numa satisfação última, a qual é ao mesmo tempo memória do gozo infantil perdido e fantasia de sua recuperação. Entretanto, como não é claro que esse prazer primário e indiferenciado tenha realmente existido, considerando que nosso único acesso a ele está fundado numa linguagem baseada em sua denegação, o Absoluto deve ser preferivelmente uma fantasia de perda do prazer proibido e não uma memória ou estágio efetivo do desenvolvimento 
infantil. Assim, faz sentido perguntar se Lacan não teria redescoberto um sonho religioso de plenitude numa fantasia de prazer perdido que ele mesmo construiu. Embora ele entenda que refutou a possibilidade de busca dialética pela plenitude, a crença nesse tipo de estado é evidente na nostalgia com a qual sua teoria do simbólico caracteriza todos os desejos humanos.

Certamente existem inúmeras razões para se suspeitar de uma concepção de desejo como esta, e é preciso lembrar que o próprio Lacan parece tê-la relativizado em momento ulterior de sua obra, voltado para uma teorização mais rigorosa sobre o registro do real, ao qual não poderemos fazer referência no contexto deste trabalho ${ }^{2}$. Talvez o problema mais importante, neste caso, se atenha ao seu ponto estrutural de base, que, como teremos a oportunidade de ver, foi justamente o principal objeto das críticas formuladas por Gilles Deleuze. Trata-se da lei proibitiva, da Lei do Pai, que parece agir de modo universal, ao ser tomada como fundamento por excelência da linguagem e da cultura. $\mathrm{O}$ que estaria pressuposto ali é que uma experiência original de prazer foi proibida e recalcada, e que o desejo emerge como falta, como um anseio ambivalente que incorpora aquela proibição, mesmo quando busca transgredi-la. Mas, poder-seia perguntar, será que o desejo é não apenas necessariamente fundado pela proibição mas também estruturado nos mesmos termos? Além disso, seria a lei assim tão rígida? E, será que a satisfação é sempre tão fantasmática?

\section{A Afirmação do Desejo Produtivo em Deleuze}

O postulado do recalque originário como constitutivo do sujeito e a conseqüente formulação do desejo como falta requerem que aceitemos esse modelo jurídico da lei como a relação político-cultural fundamental que informa a estrutura desse desejo. Nos trabalhos de Deleuze (e também de Foucault ${ }^{3}$ ), é precisamente a presunção estruturalista da primazia da lei jurídica e a formulação do desejo em termos das oposições binárias de falta e plenitude que serão questionadas. Tanto Deleuze quanto Foucault aceitam em parte o descentramento do sujeito hegeliano e os postulados da construção cultural do desejo promovidos por Lacan, mas vêem no seu programa psicanalítico um exemplo da doença que se pretende curar; isto porque eles argumentam que a reificação da lei proibitiva não é senão uma modalidade ideológica de confirmação da sua hegemonia. De formas diversas mas relacionadas, ambos recusam essa formulação do desejo em termos de negatividade, argumentando que é a afirmação, e não a negação, o que caracteriza primariamente os anseios 
humanos. Só o reconhecimento desse fato destituiria de modo absolutamente definitivo o sujeito hegeliano. Na verdade, essa negatividade do desejo seria a doença cultural sustentada tanto pela dialética quanto pela psicanálise lacaniana. Na impossibilidade de discorrer mais longamente aqui sobre as teses de Foucault, gostaria de discutir, de forma um pouco mais detalhada, as principais críticas formuladas por Deleuze.

Em seus trabalhos, Deleuze tentou reconstruir a genealogia dos desejos que se voltam sobre si, propondo uma concepção alternativa do desejo baseada na atividade produtiva e generativa. Segundo ele, o discurso que conceitua o desejo como falta fracassa na consideração da genealogia desta mesma falta, tratando sua negatividade como uma verdade ontológica universal e necessária. A leitura deleuziana pretende mostrar que o desejo se tornou uma falta em virtude de uma série contingente de condições sócio-históricas, as quais exigem e reforçam sua autonegação. Em Nietzsche e a filosofia (Deleuze, 1975), é a "moralidade escrava", típica da ideologia cultural judaico-cristã, que é considerada a responsável pela volta do desejo contra si mesmo. Mais tarde, no Anti-Édipo (Deleuze e Guattari, 1976), essa ideologia é especificada em termos contemporâneos pelos efeitos conjuntos da psicanálise (lacaniana) e das práticas de dominação próprias ao capitalismo avançado.

A partir desta perspectiva, o fundamento ontológico da falta é revelado em termos de reificação do conceito econômico de escassez, aparecendo como condição necessária da vida material inacessível às transformações sociais. Nota-se, que, em Deleuze, a crítica do discurso sobre o desejo como negatividade expõe seu caráter ostensivamente privativo como efeito de uma privação material concreta, a qual implica um tipo de ideologia reativa e contrária à vida. Já o desejo emancipado ou criador seria de outra ordem: ele estaria para além da falta e da negatividade e deveria ser visto como uma função de afirmação, geradora e produtora de vida. De acordo com Butler, poderíamos dizer que a teoria deleuziana "procede por duas vias complementares: (1) a da crítica do desejo como negatividade e (2) a da promoção de um ideal normativo para o desejo como afirmação" (Butler, 1987, p. 205). Esta última se baseia fundamentalmente na reconstrução da vontade de potência nietzscheana, posta a serviço de uma teoria de emancipação afetiva.

Deleuze argumenta que a negatividade, falta característica do desejo, é instituída por meios ideológicos, a fim de racionalizar uma situação social de hierarquia ou dominação. Em conseqüência, ele procura delimitar como o recalque 
de um desejo original, caracterizado pela plenitude e pelo excesso, culmina na sua forma derivativa faltosa e privada. A negatividade do desejo é, então, considerada o sintoma de uma história de repressão esquecida, e a desconstrução dessa negatividade promete a liberação daquele desejo mais original e generoso (abundante e farto). Deleuze rejeita a relevância universal da construção edipiana e, para se contrapor a ela, recorre ao pensamento de Nietzsche, em que a lei proibitiva é especificada como moralidade escrava judaico-cristã, a qual resulta necessariamente na volta do desejo sobre si. Segundo ele, a mesma concepção reativa das forças desejantes se expressaria, na contemporaneidade, através da lei psicanalítica do recalque primário lacaniano e da suposição capitalista de uma escassez necessária. Considerando-se que a noção deleuziana de moralidade escrava não apresenta nenhuma necessidade histórica, ela pode ser subvertida pelas forças da vontade de potência e do desejo afirmativo diante da vida, livres da coerção da lei proibitiva. Apesar da hegemonia dessa lei, Deleuze insiste em afirmar que ela não apenas pode, como deve, ser quebrada, apostando na positividade advinda de um movimento de transgressão criadora.

Baseando-se na Genealogia da moral nietzscheana, que já caracterizava a moralidade escrava como ressentimento e inveja resultantes da vontade voltada contra si mesma, a crítica deleuziana vê no sujeito hegeliano precisamente esse poder que se torna negativo através do enfraquecimento ou mutilação de seus poderes próprios. O sujeito, assim como o Eu lacaniano, não são, portanto, instâncias autônomas e autoprodutoras, mas construtos fabricados através de uma autonegação escravizada. Daí que o sujeito hegeliano, ostensivamente autônomo, é escravizado por sua própria recusa da multiplicidade não-dialética dos impulsos que sustentam sua aparente negatividade. Como ocorre em Lacan, o sujeito é mais uma vez entendido como uma defesa contra uma configuração primária do desejo, e o "trabalho do negativo" que caracteriza o desejo hegeliano é compreendido como um desejo privado de si que disfarça a genealogia de sua privação.

Para Deleuze e Nietzsche, o sujeito em Hegel se apresenta como uma falsa aparência de autonomia; e enquanto manifestação da moralidade escrava, esse sujeito seria muito mais reativo do que autoprodutivo. Justamente por isso, Nietzsche teria encontrado um ideal de autonomia mais satisfatório na vontade de potência, ou no que a sua Genealogia descreve como aqueles valores aristocráticos da força que afirma a vida, numa posição moral para além da inveja e do ressentimento. Tomando Hegel como exemplar filosófico da reação, ele afirma que "a revolta dos escravos em moral começa quando o próprio 
ressentimento se torna criador e engendra valores: o ressentimento desses seres para os quais a verdadeira reação, a da ação, está interditada e que só se ressarcem por meio de uma vingança imaginária" (Nietzsche, 2000, p. 82). Por essa razão, as grandes realizações, os verdadeiros feitos, são fontes de autoafirmação obstruídas para o tipo escravo (hegeliano) o qual, incapaz de ações autoprodutivas, está restrito às auto-subversões reativas.

A moralidade nobre de Nietzsche consiste numa afirmação da diferença que resiste à tendência dialética de assimilação numa identidade mais fechada. Isto se esclarece a partir da teoria nietzscheana das forças, tal como Deleuze a lê: "em Nietzsche, a relação essencial de uma força com outra nunca é concebida como um elemento negativo na essência. Em sua relação com uma outra, a força que se faz obedecer não nega a outra ou aquilo que ela não é, ela afirma sua própria diferença e se regozija com essa diferença" (Deleuze, 1975, p. 7). Nesses termos diferenciais, a própria vontade é um jogo de forças múltiplo que conseqüentemente não pode ser contido pela unidade dialética; essas forças representam correntes de vida, interesses, desejos, prazeres e pensamentos que coexistem sem a necessidade de uma lei repressiva ou unificadora. Por isso, a identidade não passaria de uma designação incorreta, fruto de uma má compreensão da multiplicidade enquanto característica fundamental da subjetividade. Na medida em que esta não é definida por uma lei única ou por um conceito unificador, ela na verdade mantém a oposição sem unidade, diferentemente do sujeito hegeliano, que requer que essa oposição seja assimilada em termos identitários.

Esse tipo de requisição é compreendido por Nietzsche e Deleuze como um sinal de fraqueza e decadência: se o sujeito só existe através da assimilação das oposições externas, ele não pode senão depender dessa relação negativa para a constituição reativa de sua identidade própria. Daí que lhe falta o poder de auto-afirmação característico dos tipos "fortes" e do além do homem, cujas relações com os outros transcendem a dependência radical. A vontade nietzscheana, por outro lado, não afirma a si mesma fora de um contexto de alteridade, ainda que difira do desejo hegeliano em sua aproximação fundamental da mesma. Na medida em que a diferença não é mais entendida como um prérequisito para a identidade, a diversidade não mais se apresenta como aquilo que deve ser trabalhado, suplantado ou conceituado. Mais propriamente, a diferença torna-se condição de alegria, de um sentido acentuado de prazer, de aceleração e intensificação do jogo de forças, traços que constituem o que poderíamos chamar de versão nietzscheana do gozo. 
Embora a Fenomenologia do espírito trate explicitamente do mesmo tema (Kojève, 1968, p. 51-56), nela o gozo do senhor só é alcançado sem trabalho ou só se torna possível através dos frutos do trabalho escravo. Ele tem como modelo a relação consumo / dispêndio na qual o senhor acaba por se tornar insatisfeito com sua vida de satisfações. A dependência do escravo arruína seu senso de auto-suficiência e efetividade, na medida em que a experiência de sua própria negatividade está restrita ao consumo. Em Hegel, portanto, a satisfação é claramente diferente do gozo; a primeira significa que a lei de identidade foi reafirmada, o que proporciona um tipo de gratificação estritamente conceitual, enquanto o segundo é uma questão decididamente mais sensual, mais imediata e, portanto, menos filosófica.

Na visão de Butler, Deleuze discorda de pelo menos dois destes postulados centrais hegelianos: "a formulação do gozo, em última instância, como um modo de consumo insatisfatório, e a rejeição das relações sociais hierárquicas em favor de uma noção de autonomia baseada na lei de identidade" (Butler, 1987, p. 120). Em ambos os casos, é a noção de sujeito idêntico a si que determina os parâmetros de satisfação. Uma versão de identidade como esta não passaria de mais um sintoma da moralidade escrava, na qual a diferença é apenas vivida de maneira passiva e não verdadeiramente desfrutada. A postulação de uma auto-identidade, como condição ontológica de satisfação, obstrui a afirmação da diferença enquanto tal, assim como os prazeres derivados do intercâmbio hierárquico. Nessas condições, a subjetividade dialeticamente constituída é a de um escravo, não no sentido hegeliano do termo, mas no sentido nietzscheano, ou seja, a de um tipo doente de si mesmo ao qual falta a potência da nobreza, e que através da proeza de uma transvaloração invejosa acaba por exaltar suas próprias limitações como evidência de uma moral superior (Nietzsche, 2000, p. 163-165). Esse escravo, que na verdade racionaliza sua incapacidade como força moral, é, precisamente, o sujeito hegeliano. Na medida em que a emancipação se baseia na autonomia e na auto-realização, o escravo emancipado estará restrito às coerções da auto-identidade e não conhecerá nem o prazer nem a criatividade, traços essenciais da vontade de potência e do desejo produtivo. Esse sujeito não pode senão temer ou apropriar-se de traços do mundo externo, na medida em que seu projeto fundamental e seu anseio mais profundo são atingir a auto-identidade ou a autoconsciência reflexiva. Por essas razões, não lhe é possível estar no mundo da alteridade sem medo, de forma alegre e criativa.

Ainda de acordo com Deleuze, o que Nietzsche nos propõe 
fundamentalmente são novos significados para as atividades de afirmação e negação, os quais invertem e ultrapassam as relações entre esses termos, tais como se apresentam no pensamento de Hegel. Com isso, a afirmação deixa de carregar o fardo da efetivação de uma unidade ontológica entre o que afirma e o que é afirmado, na medida em que não há mais nenhum ser fora da vontade de potência: "o ser e o nada são apenas a expressão abstrata da afirmação e da negação como qualidades (qualia) da vontade de poder" (Deleuze, 1975, p. 155). Daí em diante, todas as expectativas filosóficas de que o mundo possa ser analisado em termos de verdade e falsidade, ser e não-ser, aparência e realidade, são encaradas como sintomas de um ódio difuso para com a vida, que racionaliza a si mesmo através da imposição de falsas construções teóricas. Essas oposições conceituais teriam no fundo a pretensão de deter a vida, controlá-la e enterrá-la, salvaguardando o pensador dialético na sua posição caricatural de morto-vivo. O postulado da identidade, portanto, quer como relação entre sujeitos, entre aspectos discrepantes do mundo, ou entre o ser no mundo e sua verdade, seria apenas uma estratégia de contenção, motivada pelo temor e pelo ódio do escravo à vontade de potência enquanto princípio de vida. Segundo Deleuze, "Nietzsche não acredita nem na auto-suficiência do real nem na do verdadeiro: pensa-as como as manifestações de uma vontade, vontade de depreciar a vida, vontade de opor a vida à vida" (Deleuze, 1975, p. 153).

O esboço da posição crítica nietzscheana a partir da categoria de vontade de potência traz no seu bojo a necessidade de encararmos o desafio de uma formulação pós-hegeliana para as subjetividades desejantes. Com o seu pensar dionisíaco, Nietzsche nos oferece uma maneira de separar o desejo da negatividade e de considerar a genealogia da posição hegeliana em termos de uma moralidade escrava. A vontade de potência proporciona um modelo alternativo de desejo baseado na plenitude da vida, em sua incessante fertilidade e não na negatividade da autoconsciência. A crítica de Nietzsche à identidade também tem como consequiência promover o descentramento do sujeito autosuficiente como agente implícito e objetivo explícito do desejo. A gênese desse sujeito também é considerada por Deleuze como uma defesa contra um desejo mais primário e menos domesticado filosoficamente. Trata-se de um desejo de afirmação da vida que constitui um objetivo de emancipação diante das forças coercitivas do capitalismo e da ideologia edipiana, típicas da moralidade reativa do escravo.

Esse desejo reprimido, modelado na vontade de potência nietzscheana, é ainda atribuído ao conatus, ou potência ativa, de Spinoza, o qual, colocado no 
contexto político e cultural moderno, se torna a fonte afetiva das transformações revolucionárias (Deleuze, 1968, p. 197-213). Na ótica deleuziana, a vontade de potência é também como o desejo primário de persistir no próprio ser, tal como definido por Spinoza: ambos os desejos são potencializados e acentuados por um ser que se deixa afetar pelos fenômenos externos. Neste sentido, o desejo é fortalecido por essa capacidade de responder ao que é inevitavelmente externo. $\mathrm{Na}$ verdade, Deleuze entende a vontade de potência como uma sensibilidade desenvolvida ou uma paixão, o que faz com que, no Anti-Édipo, ele defina o desejo e o corpo em termos de forças de "atração e reprodução de intensidades" (Deleuze, 1976, p. 339). Spinoza, portanto, também oferece a Deleuze uma forma de compreender nossa relação com o mundo, a partir da intensificação de um desejo que resiste à demanda dialética de apropriação do mesmo através de uma lei identitária.

Embora Hegel critique Spinoza por não compreender a negatividade que move a autoconsciência, Deleuze parece aplaudi-lo exatamente por essa exclusão do negativo. $\mathrm{O}$ desejo é entendido como uma resposta produtiva à vida, cuja força e intensidade se multiplicam no curso de uma troca com a alteridade. A "vontade" em Deleuze não é "voluntariosa", mas responsiva e maleável, assumindo formas de organização novas e mais complexas, através da troca de forças constitutiva do desejo. Na medida em que o campo de forças é múltiplo em suas possibilidades, o desejo é menos uma luta para monopolizar o poder do que uma troca que intensifica e prolifera energia num estado de excesso. Sob o agenciamento das condições de escassez, que produzem o desejo como uma modalidade de privação, reside uma abundância plena de desejo de afirmação da vida. Para Deleuze, a tarefa política e pessoal de uma erótica pós-hegeliana é restabelecer aquela persistência espinozista e remodelá-la nos termos da vontade de potência. Deste ponto de vista, o sujeito hegeliano pode ser entendido como um produto da moralidade escrava, uma conseqüência do mal-estar cultural, assim como o resultado do agenciamento de um desejo que nega a vida.

\section{Considerações Finais}

Como esperamos poder ter mostrado, a teoria deleuziana prescreve um movimento que vai de um desejo negativo a um desejo produtivo, o qual requer que consideremos certas possibilidades de emancipação desejante. Neste sentido, é quase como se a teoria lacaniana tivesse sido politizada pela 
argumentação de que o desejo produtivo e o gozo são acessíveis à experiência humana, e de que as leis coercitivas que os governam podem e devem ser transgredidas. A insistência de Nietzsche na multiplicidade de afetos nãodialéticos desafia a possibilidade de um sujeito idêntico a si mesmo, sugerindo que a vontade de potência não possa ser reduzida à estrutura internamente complicada do desejo hegeliano. Embora Nietzsche se refira ocasionalmente a um único impulso dominante em torno do qual vários afetos e forças se organizam, Deleuze prefere claramente uma leitura da vontade de potência que resiste a uma tal unificação dos afetos. Para ele há uma diferença significativa entre um desejo internamente múltiplo, no qual a interioridade dos vários desejos sugere uma superfície unificadora de contenção, e um conjunto fundamentalmente múltiplo de desejos que não podem senão ser falsificados por algum esforço para descrevê-los como unidade.

Daí a importância da crítica de Deleuze à reificação lacaniana da lei jurídica como fundadora de toda a cultura, oferecendo, com Nietzsche, uma estratégia de subversão e transgressão dessa mesma lei. Neste sentido, seu questionamento sobre a estrutura do desejo está assentado em uma perspectiva construída em termos culturais e políticos, o que faz com que qualquer análise do desejo esteja sempre implicada na situação cultural que ela pretende explicar. Em Lacan, a promessa de uma libertação do desejo das coerções culturalmente impostas permanece impagável para sempre. Já para Deleuze, podemos apostar que a erradicação da negatividade do desejo produtivo, ou pelo menos sua colocação a serviço de uma produtividade afirmativa, culmine na viabilização de um Eros internamente diferenciado e diferencial, no qual as diferenças são entendidas como diferenciais positivos de força e não como momentos do desejo externamente relacionados entre si. Neste sentido, a teoria das forças substitui a doutrina hegeliana das relações internas, como garantia de um princípio não niilista de afirmação da vida. Se em Lacan, como vimos, o gozo permanece como a coisa em si inacessível e responsável pelos modelos estruturais de subjetividade, desejo e cultura, em Deleuze, a erótica da multiplicidade afetiva revela-se como possibilidade vital de resistência e subversão da moralidade escrava que predomina na contemporaneidade desde os tempos modernos. Se é um movimento de criação ou de transgressão, precisaríamos discutir ainda um pouco mais. Para além disso, talvez seja necessário questionar melhor de que tipo de transgressão estamos falando. Se de uma transgressão perversa, meramente negativa e fundada na normatividade da lei, ou de uma transgressão positiva, produtora de diferenças e criadora de novas possibilidades estéticas e 
éticas de existência. Esta, sim, exigirá de todos nós um verdadeiro trabalho de transvaloração e de crítica da ordem existente, para que possa se instalar com toda a sua potência de produção do novo.

\section{Referências}

BUTLER, J. Subjects of desire. New York: Columbia University Press, 1987.

DELEUZE, G. Spinoza et le problème de l'expression. Paris: Minuit, 1968. . Nietzsche e a filosofia. Rio de Janeiro: Editora Rio, 1975.

DELEUZE, G.; GUATTARI, F. O anti-Édipo. Rio de Janeiro: Imago, 1976.

FREUD, S. Pulsiones y destinos de pulsión. In: Obras completas. Buenos Aires: Amorrortu, 1994. v. 14.

HEGEL, W. F. La phénoménologie de l'esprit. Paris: Aubier, 1941.

HYPPOLITE, J. Figures de la pensée philosophique. Paris: PUF, 1971.

KOJÈVE, A. Introduction à la lecture de Hegel. Paris: Gallimard, 1968.

LACAN, J. Écrits. Paris: Seuil, 1966.

. Da estrutura como intromistura de um pré-requisito de alteridade e um sujeito qualquer. In: MACKSEY, R.; DONATO, E. (Org.). A controvérsia estruturalista. São Paulo: Editora Cultrix, 1976. p. 198-212.

. O Seminário: os quatro conceitos fundamentais da psicanálise. Rio de Janeiro: Zahar Editores, 1979. v.11.

NIETZSCHE, F. La généalogie de la morale. Paris: Librairie Générale Française, 2000.

\section{NOTAS}

\footnotetext{
${ }^{1}$ Psicanalista, doutor em Saúde Coletiva pelo IMS-UERJ, professor assistente do Programa de Pósgraduação em Psicologia Clínica da Pontifícia Universidade Católica do Rio de Janeiro (PUC-Rio).

${ }^{2}$ Para uma síntese da teoria lacaniana sobre o real, remetemos o leitor aos seguintes artigos de Jacques-Alain Miller: "Les six paradigmes de la jouissance", em La cause freudienne, n. 43, Paris:
} 
Seuil, 1999; "L'ex-istence“, em La cause freudienne, n. 50, Paris: Seuil, 2001; "Le dernier enseignement de Lacan“, em La cause freudienne, n. 51, Paris: Seuil, 2001.

${ }^{3}$ Como aqui vamos nos ater fundamentalmente ao pensamento de Deleuze, remetemos o leitor a pelo menos uma obra de referência para essas críticas: Foucault, M. História da sexualidade I, Rio de Janeiro: Graal, 1980.

\section{ABSTRACT}

The Law of Desire and Productive Desire: Transgression of Order or Affirmation of Difference?

This article is intended to confront the concepts of desire in the theories of Jacques Lacan and Gilles Deleuze, respectively, presenting several differences between a Hegelian model, based on law, fault, and negativity, and a Nietzschean model, based on affirmation and production. It this becomes possible to conceive of two forms of subjectivation, likewise diverse, one centered on an oedipal view, and another deriving from the critique of this matrical model. The purpose is thus to confront the notion of a negative transgression, based on the denial of law and order, with a concept of creative or positive transgression, based on the affirmation of difference.

Key words: Desire; law; transgression; Lacan; Deleuze.

Recebido em: 05/02/2004.

Aprovado em: 05/04/2004. 